\title{
The CO2 conditions within the baby cots of day care centres
}

\author{
Gert-Jan Braun ${ }^{1}$ and Wim Zeiler ${ }^{1, *}$ \\ ${ }^{1}$ TU Eindhoven, Department of the Built Environment, 5600 MB Eindhoven, Netherlands
}

\begin{abstract}
The indoor quality of an occupied space is very important for the well-being of its occupants, especially in the case of young children. Although nowadays little children spend a lot of their time in day care centres, relatively little is known about the effects of different indoor environmental factors present in these day care centres. Therefore this research investigated the indoor air quality of the sleeping accommodation of two Dutch day care centre as well as the conditions with the baby cots. Besides an extensive literature research actual measurements were performed in two day care cent to find out the indoor air conditions within baby cots. The results of the detailed studies were compared with the results of earlier Dutch studies in day care centres. Although, our latest findings were not as bad as results from our earlier case studies, still more attention is needed to get a better understanding of the current situation in which babies sleep.
\end{abstract}

\section{Introduction}

Young children, and their immune system, are continuously under development. Adverse conditions could influence this development [1], or might even increase the risk of sudden infant death [2,3]. Children are more vulnerable to airborne pollution due to the fact that their airways are narrower than adults, they have markedly increased needs for oxygen relative to their seize, they breathe more rapidly and inhale more pollutants per pound of body weight [4]. Babies and little children spend a lot of their time in day-care centers while parents are at work. The infants normally stay at a child day-care centre until their fourth birthday. Strangely enough little is known about the indoor environmental conditions in these day-care centers $[5,6,7,8,9,10,11$, 12]. This while a healthy environment is very important for the development of infants and especially their longs as such they are the most vulnerable group of our population. Table 1 provides an overview of some studies, in most cases between 20 up to $75 \%$ of all measured daycare centers had $\mathrm{CO}_{2}$ concentrations well above the recommended level by the Dutch government of 1000 ppm in class rooms and $800 \mathrm{ppm}$ in sleeping rooms.

In most studies the overall $\mathrm{CO}_{2}$ level is measured in the class rooms and in some also in the bedroom. Therefor it was decided to examine especially the ventilation of the daycare bedrooms in detail. The objective of this research is to determine $\mathrm{CO}_{2}$ concentration in the breathing zone of a sleeping infant of baby cots used in child day care centres and see if they meet the demands in the Dutch building code of 2012. Field studies have been done among the different types of baby cots in different daycare centers to measure the $\mathrm{CO}_{2}$ concentrations inside these baby cots [13,14] of which an overview was made [17]
Table 1. Overview of $\mathrm{CO}_{2}$ concentrations in daycare centers from different studies

\begin{tabular}{|l|l|l|l|l|}
\hline Year & Location & Number & $\begin{array}{l}\text { Average } \mathrm{CO}_{2} \\
{[\mathrm{ppm}]}\end{array}$ & Reference \\
\hline 2005 & Netherlands & $51-62$ & $\begin{array}{l}920 \text { (bedrooms) } \\
1297 \text { (class } \\
\text { room) }\end{array}$ & {$[5]$} \\
\hline 2009 & Netherlands & 60 & 1452 & {$[7]$} \\
\hline 2011 & Latvian & 4 & 731 & {$[8]$} \\
\hline 2011 & Paris & 28 & 933 & {$[9]$} \\
\hline 2012 & Montreal & 21 & 1333 & {$[17]$} \\
\hline 2014 & Portugal & 52 & 1563 & {$[10]$} \\
\hline 2016 & Italy & 1 & 1100 & {$[11]$} \\
\hline 2016 & Europe & 4 & 1128 & {$[12]$} \\
\hline
\end{tabular}

In this paper the results of further investigations in two more modern daycare centers are presented. The results of the measured $\mathrm{CO}_{2}$ concentrations inside baby cots of day-care centers made it clear why it is important to focus also on the ventilation effectiveness inside baby cots and not only on the ventilation rates in general. These effects can lead to $\mathrm{CO}_{2}$ concentrations which can be on average around $25 \%$ (with in some situations even up to nearly $60 \%$ higher) than the average concentrations in the sleeping rooms of the day-care centers from the extensive research by Versteeg in 2009 [7].

\section{Methods}

As stated in section one, the goal of this research is to determine what the $\mathrm{CO}_{2}$ concentration are near a sleeping infant and to see if they meet the current demand of the Dutch building code 2012. To determine this measurements were performed in different type of baby cots in two day care centres The purpose of these

*Corresponding author: w.zeiler@tue.nl 
measurements was to obtain enough $\mathrm{CO}_{2}$ data to compare the conditions within a specific baby cot and to determine if the differences between these baby cots are significant and accountable for possibly higher $\mathrm{CO}_{2}$ concentrations. In our earlier research $[13,14]$, different types of baby cots were monitored inside the day care centre, see Figure 1. The first type, a crib is used for children in the age of 2 -4 and which tend not to get out of bed while sleeping. The second type, the bedstead, is used by both new bourns as children in the age of $2-4$. The last type was the bunk bed used, top and bottom, with children in the age of 10 weeks up to 2 years.
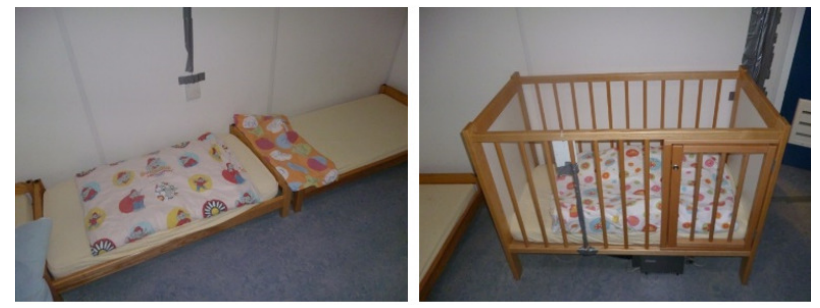

Crib

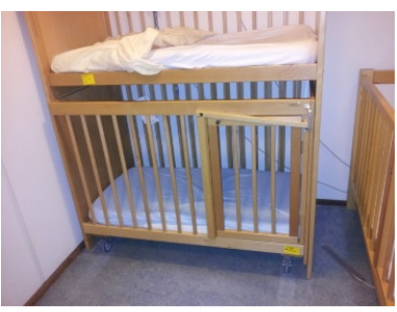

Bedstead

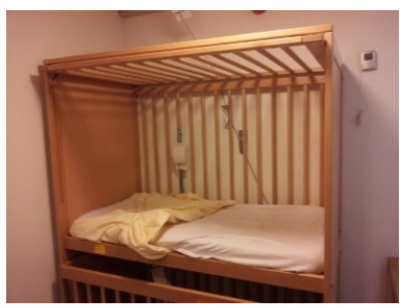

Bottom bunk bed

Top bunk bed

Figure 1. Different types of baby cots

\subsection{Measurement setup}

In the research of de Waard [13], the breathing zone was determined to be $\pm 0.3 \mathrm{~m}$. This is therefore the distance that was aimed to apply in the 'practical conditions'. The general setup can be seen in Figure 2.

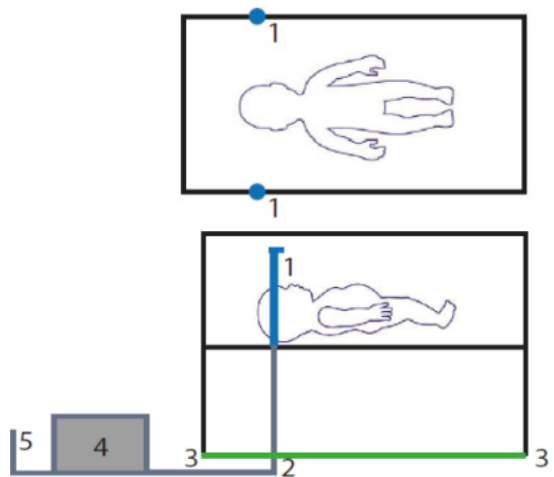

Figure 2. General measurement setup

1. Two $\mathrm{CO}_{2}$ sensors

2. Cable bundler

3. Two pressure sensors

4. Central box

5. Mains supply
The equipment used during the measurement is displayed in Table 2.

Table 2. Measurement equipment

\begin{tabular}{|l|l|l|l|}
\hline Measurement & Device & Interval & Inaccuracy \\
\hline $\mathrm{CO}_{2}$ & $\begin{array}{l}\text { SBA-\% } \mathrm{CO}_{2} \\
\text { Analyser }\end{array}$ & $1 \mathrm{sec}$ & $\pm 20 \mathrm{ppm}$ \\
\hline Data logging & $\begin{array}{l}\text { Squirrel 2020 } \\
\text { series }\end{array}$ & $1 \mathrm{sec}$ & $\pm 0,075 \%$ \\
\hline
\end{tabular}

To ensure to safety of the infant inside (and outside) the crib, none of the equipment was placed inside the crib. Also all the wires where made unreachable from inside the crib.

\subsection{Measurements}

The measurement results are gathered from the 18th of June until the 21st of June. All the measurement took place in the Netherlands, in 'den Haag'. In total two location were measured over a period of two days, [1] respectively [2] in table 5, each at a different room, these locations can be seen in Table 3. Both locations where recently renovated and where mechanically ventilated, meeting the ventilation demands of the Dutch building code 2012.

Table 3. Measured locations

\begin{tabular}{|l|l|l|}
\hline Date & Location & Room \\
\hline $18-06-2018$ & A & 1 \\
\hline $19-06-2018$ & A & 2 \\
\hline $20-06-2018$ & B & 3 \\
\hline $21-06-2018$ & B & 4 \\
\hline
\end{tabular}

All date generated during the measurements were stored on a logger. Afterwards the logger can be read out and the data can be used for analysis. During the measurement a logbook was kept to store all the actions that might have an effect on the registered data. For an example of this logbook see Table 4.

Table 4. Example logbook location A room 2

\begin{tabular}{|l|l|}
\hline Time & Action \\
\hline 9.17 & Measurement started \\
\hline $\begin{array}{l}9.58- \\
10.07\end{array}$ & Test baby is placed in the crib (and 4 others) \\
\hline $\begin{array}{l}10.55- \\
10.58\end{array}$ & Baby is taken out of the crib (and 4 others) \\
\hline 11.00 & Measurement setup is checked \\
\hline 12.00 & One baby is placed in other crib \\
\hline 13.15 & Another baby is placed in the crib (stacked crib) \\
\hline 15.01 & 2 babies are taken out of their crib \\
\hline 15.05 & Test baby and four other baby are placed in their bed \\
\hline 15.07 & Measurement setup is checked \\
\hline 16.14 & Test baby and all the other babies are taken out of \\
\hline 16.21 & the crib \\
\hline 16.32 & Fine particle measurement installed \\
\hline
\end{tabular}




\section{Results}

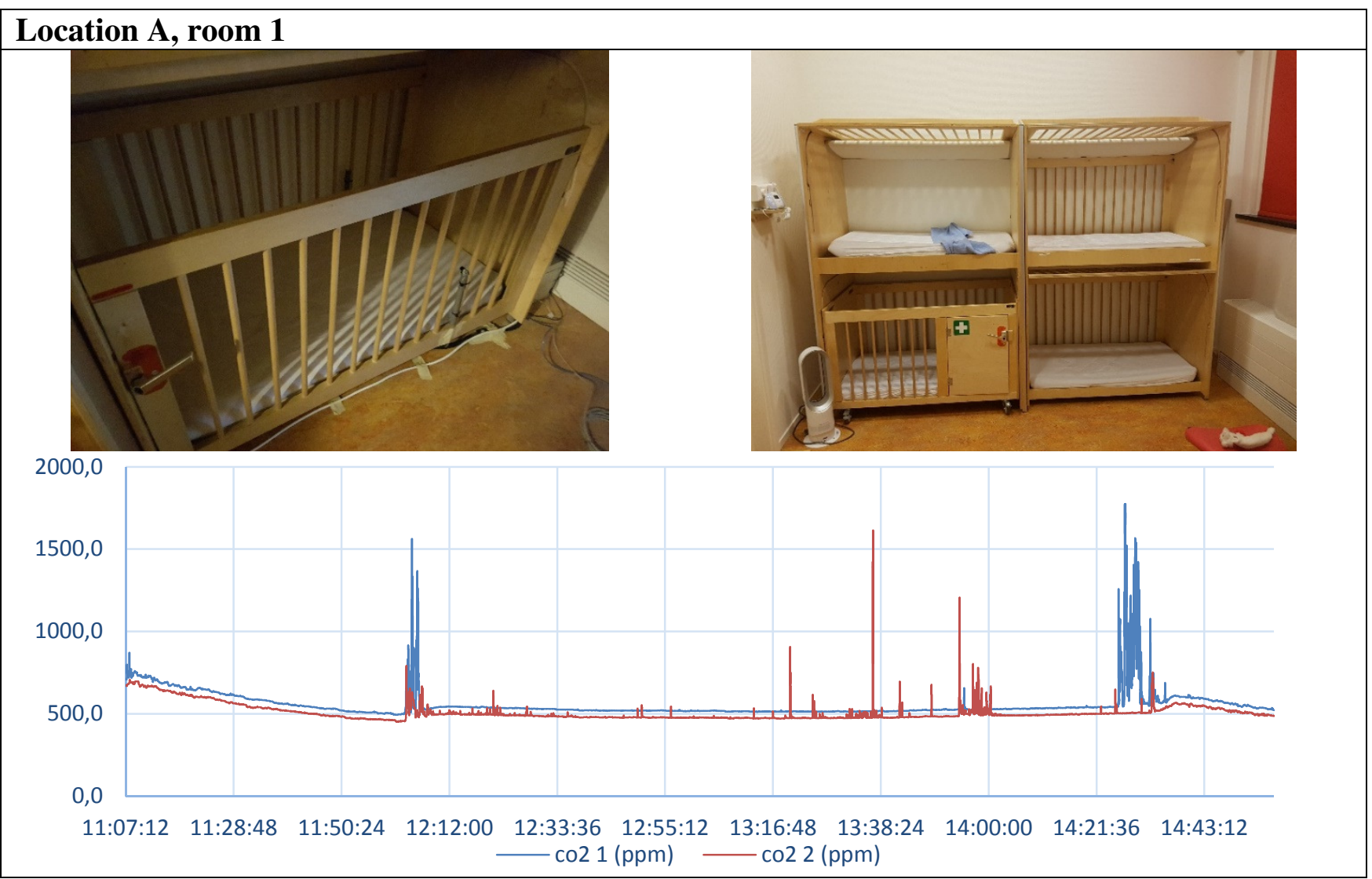

Figure 3. Measurement setup and results location A, room 1

\section{Location A, room 2}

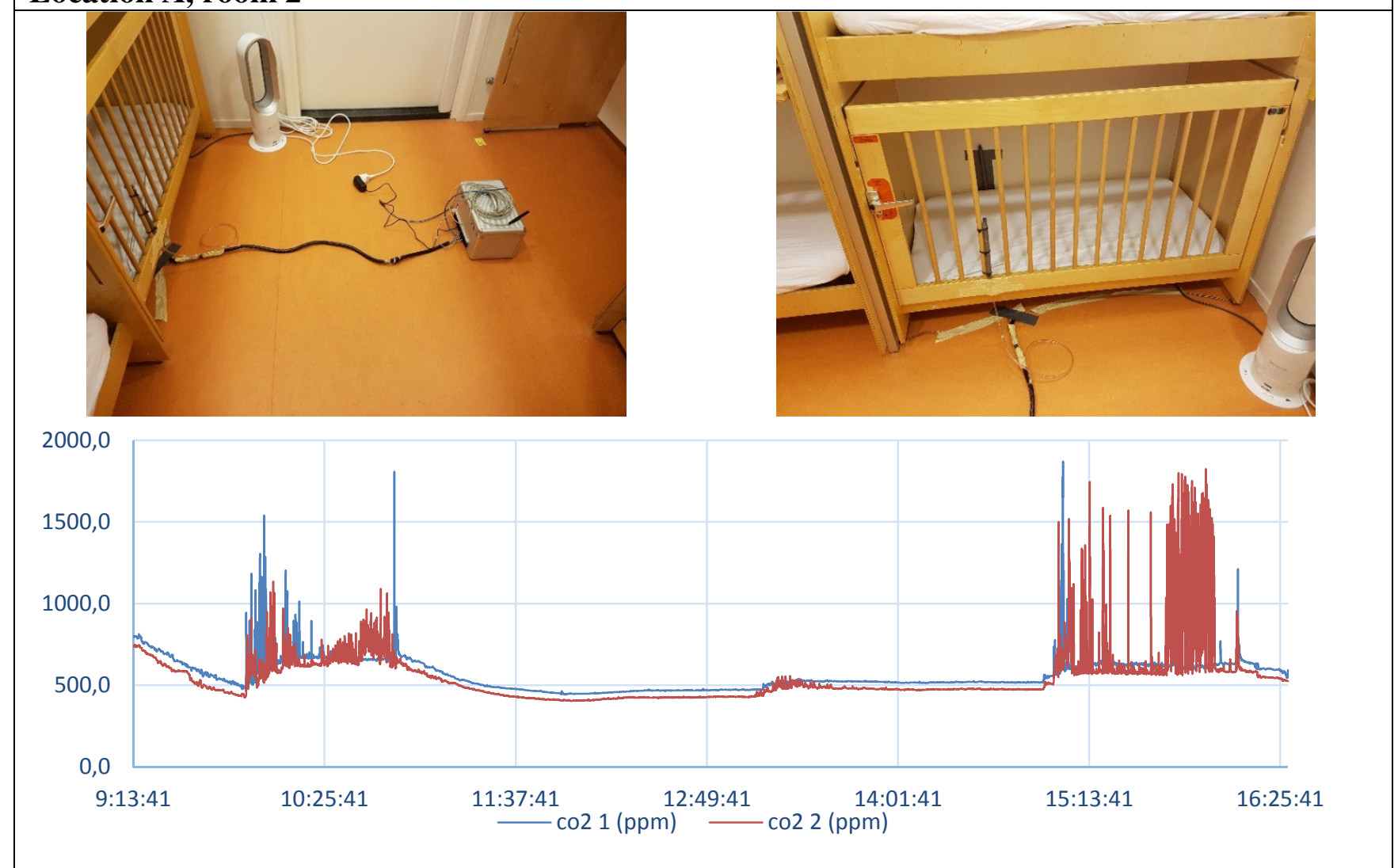

Figure 4. Measurement setup and results location A, room 2 


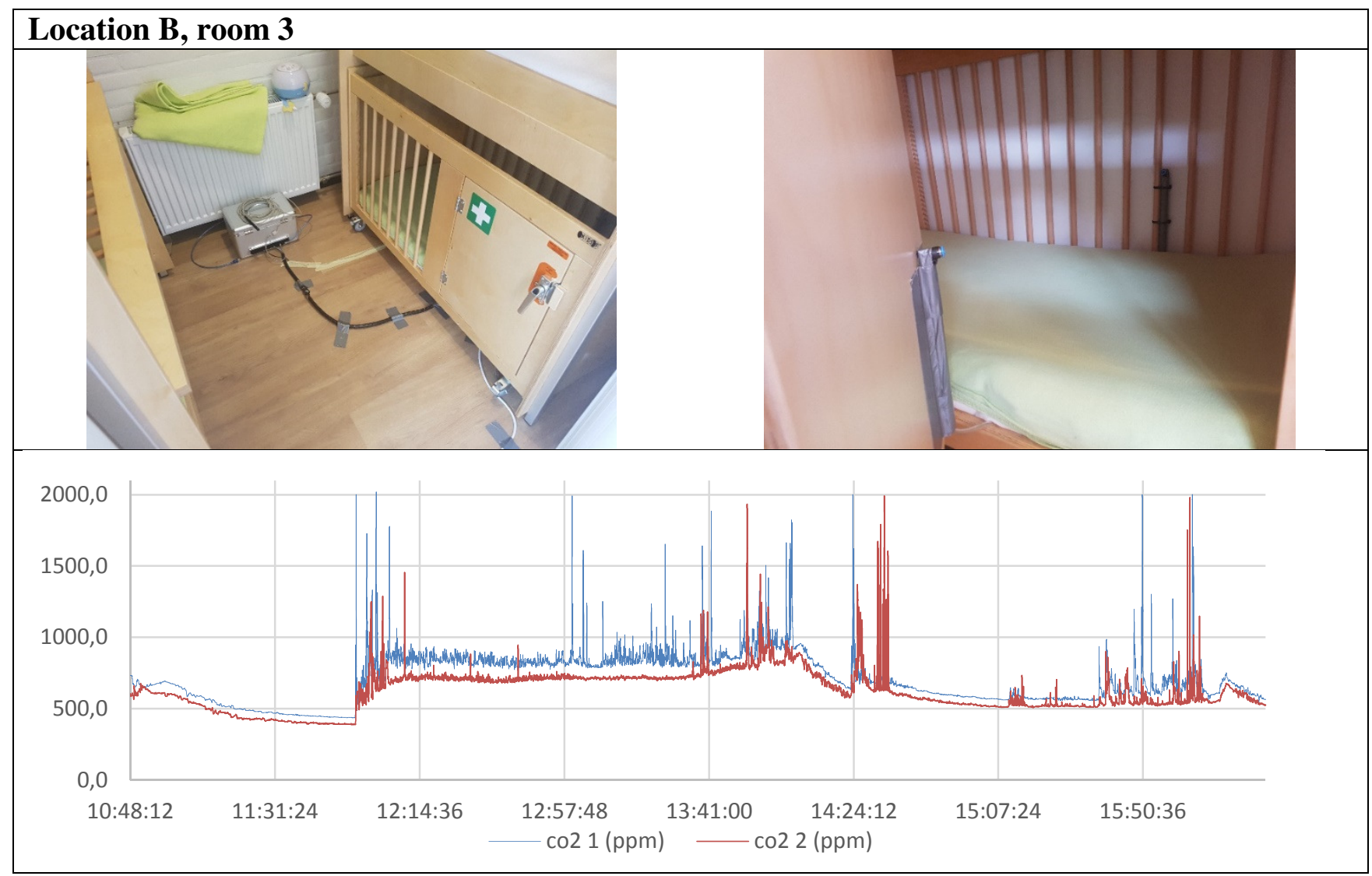

Figure 5. Measurement setup and results location B, room 3

\section{Location B, room 4}
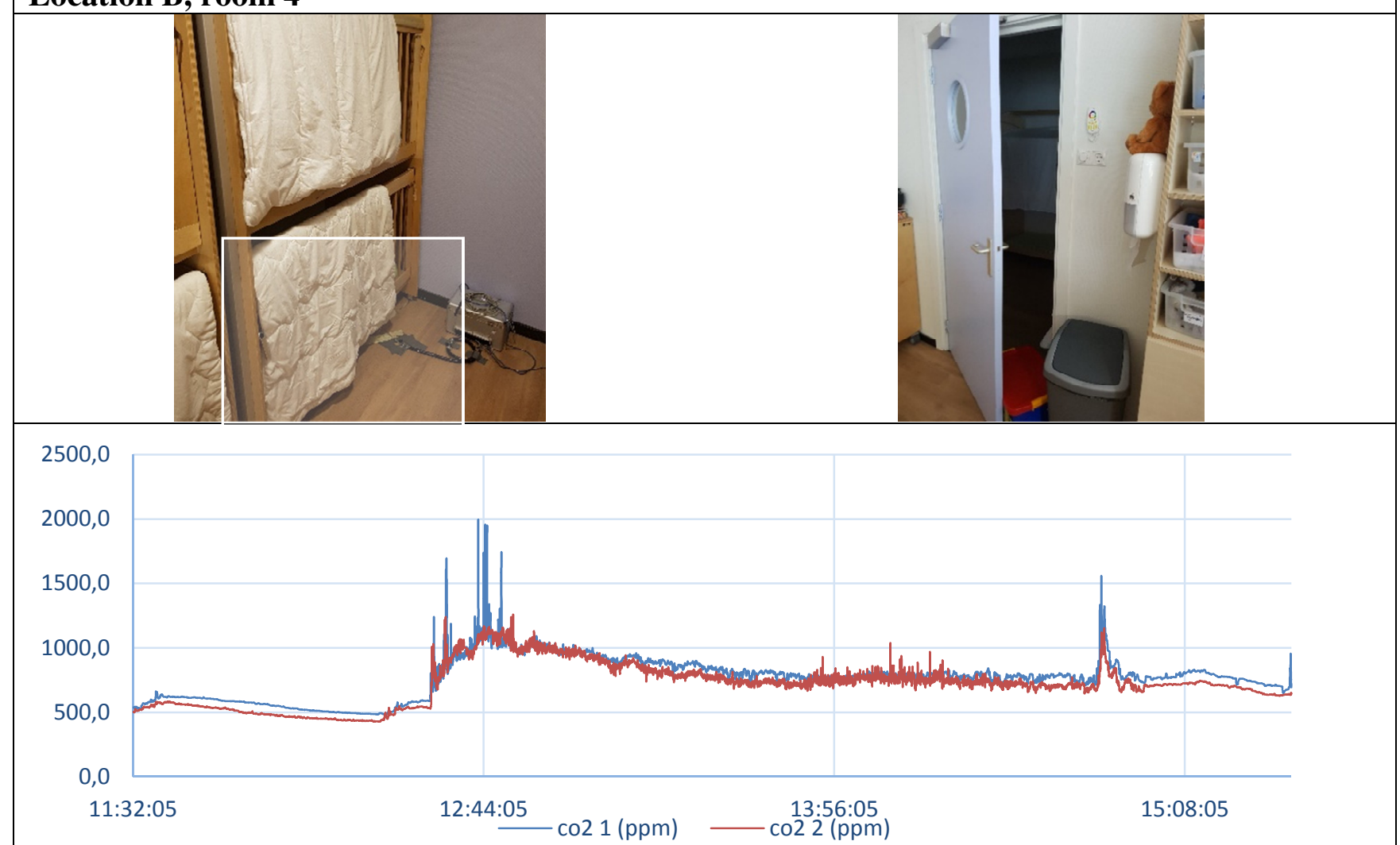

Figure 6. Measurement setup and results location B, room 4 


\section{2. $\mathrm{CO}_{2}$ levels}

The $\mathrm{CO}_{2}$ concentration during nap-time (the infant is inside the crib) is summed up in Table 5. Each percentage resembles the amount of time during nap-time that the $\mathrm{CO}_{2}$ concentrations are within the listed classes. The listed classes are based on the test values for ventilation in schools and child daycares [15]. The classes can be described as:

- A: Very good

- B: Good

- C: Acceptable

- D: Insufficient

- $\quad$ E: Very poor

Table 5. CO2 concentrations during nap-time (GGD)

Legenda: A.R1[1], means Location A room 1 measurement session 1

\begin{tabular}{|c|c|c|c|c|c|}
\hline Class & $\mathrm{A}$ & B & $\mathrm{C}$ & $\mathrm{D}$ & $\mathrm{E}$ \\
\hline $\mathrm{CO}_{2}[\mathrm{ppm}]$ & $<650$ & $\begin{array}{l}650- \\
800\end{array}$ & $\begin{array}{l}800- \\
1000\end{array}$ & $\begin{array}{l}1000- \\
1400\end{array}$ & $\begin{array}{l}> \\
1400\end{array}$ \\
\hline A.R1 [1] & $97.6 \%$ & $0.9 \%$ & $0.7 \%$ & $0.6 \%$ & $0.2 \%$ \\
\hline A.R1 [2] & $99.4 \%$ & $0.5 \%$ & $0.1 \%$ & $0.0 \%$ & $0.0 \%$ \\
\hline $\begin{array}{l}\text { A.R2 [1] } \\
\text { Nap } 1\end{array}$ & $7 \%$ & $91 \%$ & $2 \%$ & $0 \%$ & $0 \%$ \\
\hline $\begin{array}{l}\text { A.R2 [2] } \\
\text { Nap } 1\end{array}$ & $47 \%$ & $46 \%$ & $7 \%$ & $0 \%$ & $0 \%$ \\
\hline $\begin{array}{l}\text { A.R2 [1] } \\
\text { Nap 2 }\end{array}$ & $95 \%$ & $4 \%$ & $0 \%$ & $0 \%$ & $0 \%$ \\
\hline $\begin{array}{l}\text { A.R2 [2] } \\
\text { Nap } 2\end{array}$ & $67 \%$ & $8 \%$ & $6 \%$ & $13 \%$ & $5 \%$ \\
\hline $\begin{array}{l}\text { B.R3 [1] } \\
\text { - Nap 1 }\end{array}$ & $0 \%$ & $7 \%$ & $88 \%$ & $4 \%$ & $1 \%$ \\
\hline $\begin{array}{l}\text { B.R3 [2] } \\
\text { Nap } 1\end{array}$ & $0 \%$ & $87 \%$ & $12 \%$ & $1 \%$ & $0 \%$ \\
\hline $\begin{array}{l}\text { B.R3 [1] } \\
\text { - Nap } 2\end{array}$ & $70 \%$ & $28 \%$ & $1 \%$ & $1 \%$ & $0 \%$ \\
\hline $\begin{array}{l}\text { B.R3 [2] } \\
\text { Nap } 2\end{array}$ & $93 \%$ & $5 \%$ & $1 \%$ & $1 \%$ & $0 \%$ \\
\hline B.R4 [1] & $0 \%$ & $44 \%$ & $44 \%$ & $12 \%$ & $0 \%$ \\
\hline B.R4 [2] & $0 \%$ & $62 \%$ & $28 \%$ & $11 \%$ & $0 \%$ \\
\hline
\end{tabular}

The results from Table 5 were added up in Figure 7 and Figure 8 . In figure 7 and 8 , the left column represents the measurement position inside the crib attached to the bars, the right column represent the measurement position at the wall.

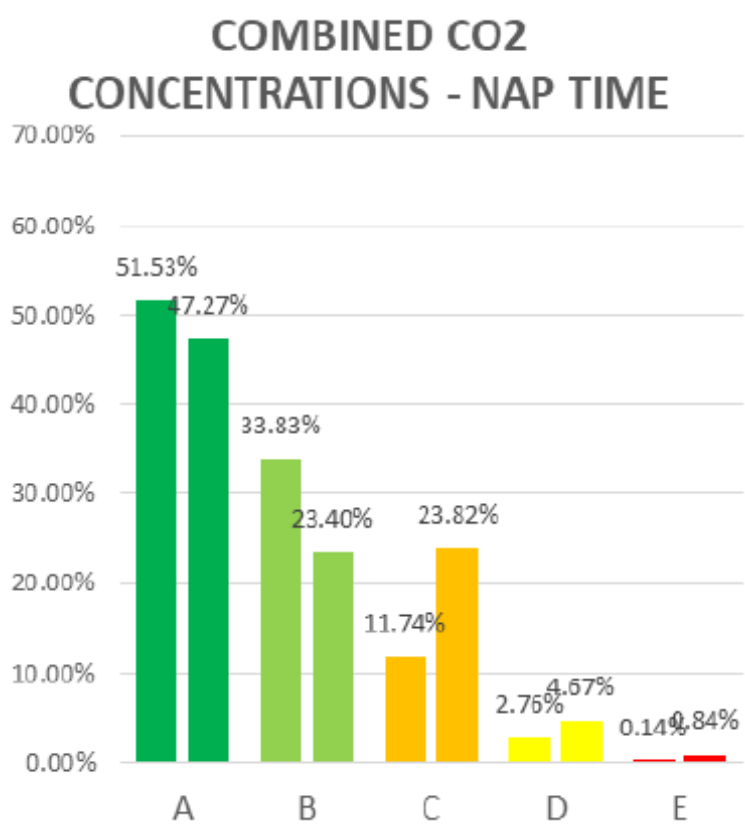

Figure 7. $\mathrm{CO}_{2}$ concentrations during nap-time, all measurements

However it is advised to take actions if this occurs too much.

During the measurements in location $\mathrm{B}$ room 3 , the ventilation unit malfunctioned in the first nap-period. When these values are excluded, see Figure 8, the $\mathrm{CO}_{2}$ concentrations meet the conditions for class A and B for $85 \%$ (bars) and $85 \%$ (wall) of the time. It also can be seen that the class A increases from 52\% and $47 \%$ to $64 \%$ and $58 \%$. The undesired class $\mathrm{C}$ is also significantly lower.

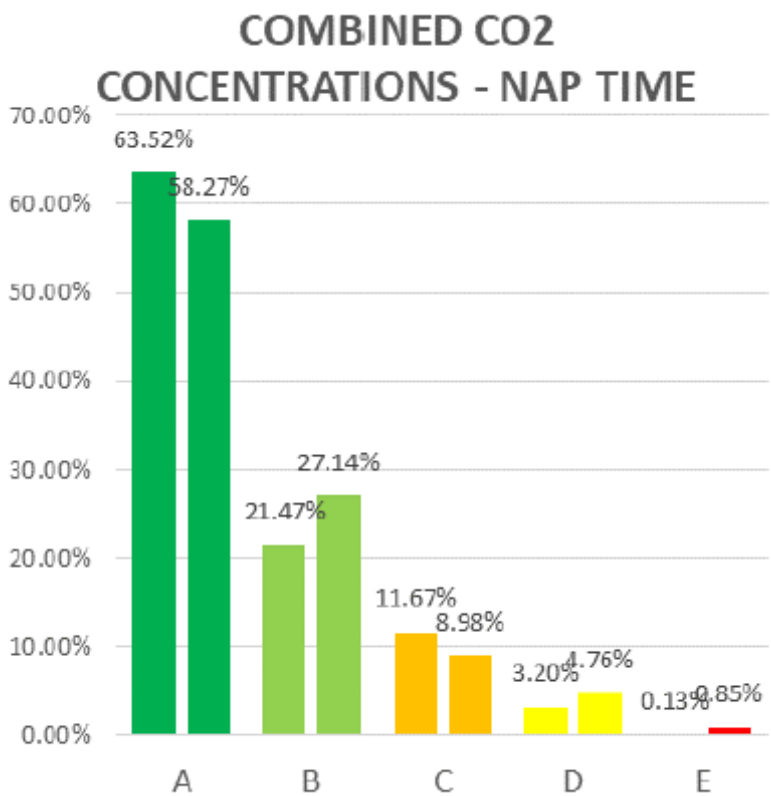

Figure 8. $\mathrm{CO}_{2}$ concentrations during nap-time, Nap $1 \mathrm{~B}$ R3 excluded

The class $\mathrm{D}$ and $\mathrm{E}$ conditions also occur in both figures, however this is a small percentage. During the test period at the TU/e it was noticed that if someone is close to the sensors, and breaths directly into the air intake, the

\footnotetext{
*Corresponding author: w.zeiler@tue.nl
} 
values spike tremendously. As explained before, during the experiment the children were put to bed, but where not asleep directly. In some cases it was noticed that the children would stand directly to one of the sensors, especially the sensor attached to the bars.
In Table 4 it can be seen class $\mathrm{D}$ and $\mathrm{E}$ are most reached during Nap 2 in location A room 2, these values are displayed in Figure 7. During the end of the sleeping period the values of above $1000 \mathrm{ppm}$ are mostly reached.

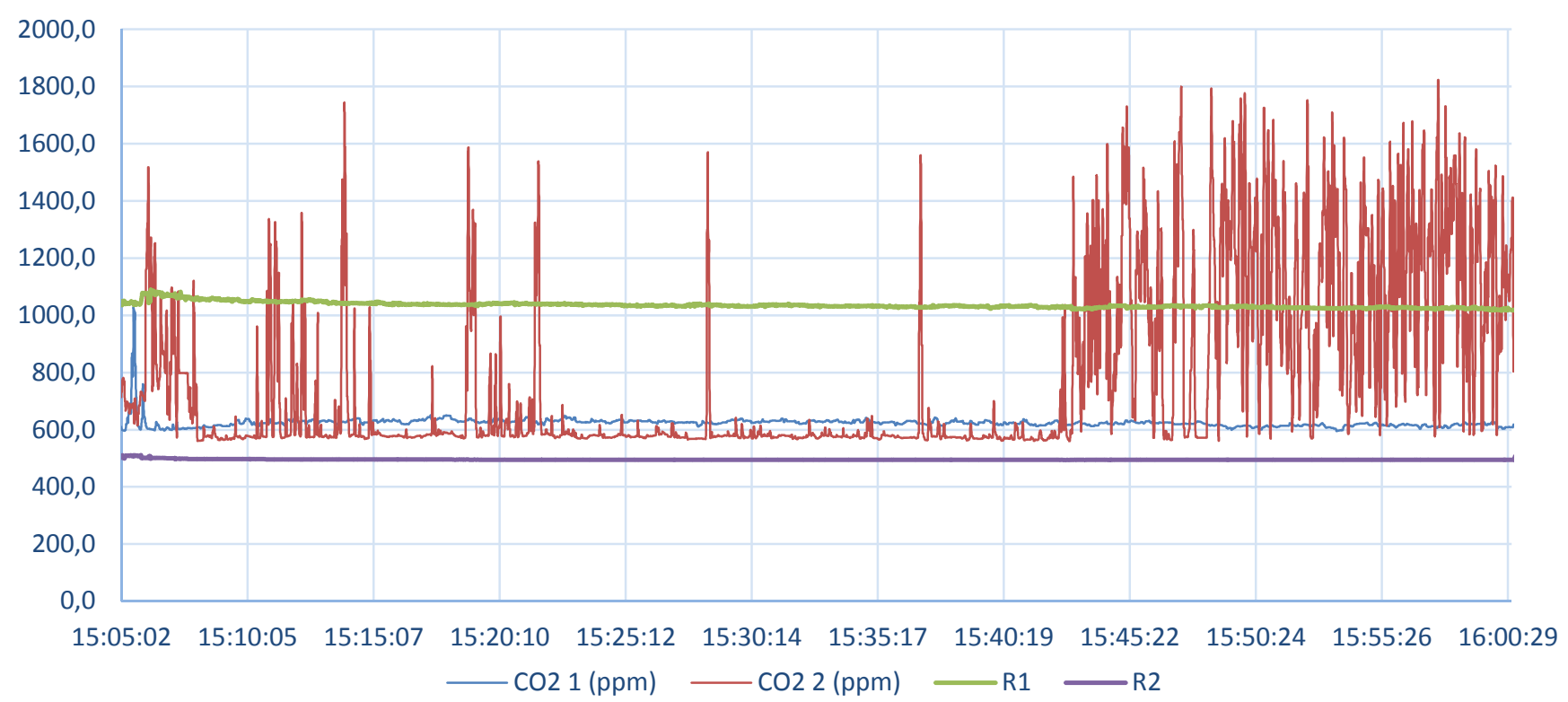

Figure 9. $\mathrm{CO}_{2}(\mathrm{PPM})$ vs. movement - Location A, room 2

\section{Discussion and Conclusions}

It should be noted that the results given here are only applicable to the measurement period used in this research: Summer. Measurements at another time of the year, for instance during the winter, can lead to other results and possibly to other conclusions because then the natural supply of fresh air will be limited by the cold outside temperature and danger of draft. The detailed measurements of $\mathrm{CO}_{2}$ concentrations within the breathing zones of the babies, incidentally showed difference in results caused by the location and the type of baby cot.

The measurement setup had to be installed in a practical condition, the desirable measurement distance to the head of an infant is $0.3 \mathrm{~m}$, at the researched location this was significantly higher, around $0.4 \mathrm{~m}$ (also depending on the position of the baby). This to ensure the safety of the infants, no measurement equipment could be placed inside the cribs. The ventilation amounts that were applied during nap-time, led to indoor air quality conditions that met the guidelines of the Dutch Building Code and even the more strict guidelines of local health authorities GGD. The final classification for each investigated room is calculated according the guidelines by the GGD (2006) [15], therefore a percentile of $98 \%$ is taken into account. The results are displayed in Table 6. 'B 3. - Nap 1' can be neglected due to the malfunctioning of the air handling unit. However, this clearly shows the positive effect of the applied mechanical ventilation system.
Table 6. Final classification (GGD) for each baby cot.in the different rooms on the 2 locations $\mathrm{A}$ and $\mathrm{B}$.

\begin{tabular}{|l|l|l|}
\hline $\begin{array}{l}\text { Location, } \\
\text { (sensor 1 and 2) }\end{array}$ & $\mathrm{CO}_{2}[\mathrm{ppm}]$ & Class \\
\hline A.1. & 514.7 & A \\
\hline A.2.-Nap 1 & 674.1 & B \\
\hline A.2.-Nap 2 & 681.4 & B \\
\hline B.3.-Nap 1 & 800.7 & C \\
\hline B.3.-Nap 2 & 590.1 & A \\
\hline B.4. & 821.6 & C \\
\hline
\end{tabular}

This article presents the results of $\mathrm{CO} 2$ concentrations inside different baby cots of 2 day-care centers and shows that the daycare facilities performed according to the GGD classification. However there were increased CO2 levels by occupied cribs compared to empty cribs as well as there was negative effects of specific location of the cribs in the corner of rooms. Therefore, it is important to do more research on the ventilation effectiveness inside of the baby cots and not only on the ventilation rates in the room in general. The effects can lead to $\mathrm{CO} 2$ concentrations which can be on average around $25 \%$ (with in some situations even up to nearly $60 \%$ higher) than the average concentrations in the sleeping rooms of the daycare centers. This clearly shows the importance of these factors and why it is not sufficient to just measure an overall CO2-concentration as an indicator of the Indoor Air Quality within day-care centers. 


\section{References}

1. P J Louhiala, N Jaakkola, R Ruotsalainen, and J J JaakkolaDepartment of Public Health, University of Helsinki, Finland. "Form of day care and respiratory infections among Finnish children.", American Journal of Public Health 85, no. 8_Pt_1 (August 1, 1995): pp. 1109-1112.

2. Corbyn J.A., 1993, Sudden infant death due to carbon dioxide and other pollutant accumulation at the face of a sleeping baby, Medical Hypotheses 41: 483-494

3. Corbyn J.A., 2000, Mechanism of sudden infant death and the contamination of inspired air with exhaled air, Medical Hypotheses 54(3); 345-352

4. Etzel R.A., 1996, Air pollution hazards to children, Otolaryngology - Head and Neck Surgery, February 1996

5. Haans L., Boerstra A.C., 2005, Dutch daycare centers, Proceedings Indoor Air and Climate, Beijing, China

6. Zurami M.S., Thom K.W., Chew F.T., Ooi P.L., 2007, The effect of ventilation strategies of child care centers on indoor air quality and respiratory health of children in Singapore, Indoor Air 17: 317-327.

7. Versteeg H., 2009, Onderzoek binnenmilieu kindercentra, LBPILichtveld Buis \& Partners

8. Stakevica G., Lesinskis A., 2011, Indoor Air Quality and Thermal Comfort in Latvian Daycare Centers, Scientific Journal of Riga Technical University

9. Roda C., Barral S., Ravelomanantsoa H., Dusséaux M., Tribout M., Moullec Y. Le, Momas I., 2011, Assessment of indoor environment in Paris child day care centers, Environmental Research 111: 1010-1017

10. Mendes A, Aelenei D., Carreiro-Martins P., Agular L., Pereira C., Neves P., Azevedo S., Cano M., Prooenca C., Viegas J., Siva S., Mendes D., Neuperth N., Teixeira J.P., 2014, Environmental and ventilation assessment in Child Day Care Centers in porto: the ENVIRH Project, J.Toxicol Environ Health A:77(14-16): 931-943

11. Pagliano L., Armani R., Sangalli A., Causone F., Pietrobon M., 2016, Analysis of ventilation strategies for nearly zero energy retrofit of a day care center, Proocedings Clima 2016, Aalborg, Denmark

12. Wargocki P., Hviid C.A., Skupien A., 2016, Do New Renovated Schools and Kindergartens Secure Sufficient High Indoor Environmental Quality?, Proceedings Clima 2016, Aalborg, Denmark

13. De Waard M.M., 2014, influence of bedroom configurations on the $\mathrm{CO}_{2}$-concentrations of the surrounding air near a sleeping infant, MSc-thesis, TU Eindhoven, Netherlands
14. Kruisselbrink T.W., 2015, $\mathrm{CO}_{2}$ Concentration in the Vicinity of Sleeping Infants at Dutch Daycare Centers, Master project, TU Eindhoven, Netherlands

15. GGD Nederland, 2006, Toetswaarden voor ventilatie in scholen en kindercentra. GGD Nederland, werkgroep binnenmilieu.

16. St-Jean M., St-Amand A., Gilbert N.L., Soto J.C., Guay M., 2012, Indoor air quality in Montreal daycare centers, Canada, Environmental Research 118:17

17. Zeiler W., The indoor environmental quality in Dutch day care centres: The effects of ventilation on the conditions within the baby cots, Proccedings Roomvent \& Ventilation 2018, Espoo, Finland 